\title{
On the cardinal system in Italian Sign Language (LIS) ${ }^{1}$
}

\author{
AUTHORS' NAMES
}

(to be added)

This article has been published in a revised form in Journal of Linguistics [http://doi.org/10.1017/ S0022226718000658]. This version is free to view and download for private research and study only. Not for re-distribution or re-use. (c) Cambridge University Press.

\section{Abstract}

This paper offers a comprehensive discussion of the cardinal system of Italian Sign Language (LIS). At the lexical level, we present the different formational strategies used to generate cardinal numerals and we provide evidence that in the younger generations of signers, the sign ONE has lost the function of indefinite determiner and is now used as cardinal only. At the syntactic level, we show that the attested variation in order between the cardinal and the noun is in part due to definiteness and contrastive focus. We account for this variation within the cartographic approach to syntax. Finally, we offer a principled explanation for the reason why cardinals inside Measure Phrases are not subject to word order variation, but always precede the measure noun.

\section{Keywords}

Italian Sign Language, cardinal numerals, measure phrases, (in)definiteness

1 ACKNOWLEDGMENTS (to be added) 


\section{INTRODUCTION}

Italian Sign Language (LIS) exhibits the syntactic properties of a typical head-final language, at least in the clausal domain (Cecchetto, Geraci \& Zucchi 2006). However, according to corpus-based studies, word order flexibility is attested to some degree in the syntax of the nominal domain (Mantovan \& Geraci 2017), wh- interrogatives (Branchini, Cardinaletti, Cecchetto, Donati \& Geraci 2013), and basic sign order in declarative sentences (Branchini \& Geraci 2011).

In this paper, we focus on a particular category of nominal modifiers, namely cardinal numerals, which has not been systematically examined yet. We provide new evidence showing that: i) cardinals are found both in pre- and post-nominal position, as in (1); ii) the sign ONE is not ambiguous between a cardinal and indefinite determiner use at least in the younger generation of signers, as in (2); iii) Measure Phrases have a fixed syntactic distribution, as in (3). For the sake of clarity, in the examples below, cardinals are boldfaced and the relevant nominal expression is indicated by square brackets. Following the general convention for sign language, the glosses for signs are in small caps.

\section{(1) a. Cardinal $>\mathbf{N}$}

SEAT LIMIT [TEN PEOPLE]

'The capacity is limited to 10 passengers.'

\section{b. $\mathbf{N}>$ Cardinal}

IX-1 [PASSION TWO] SNOWBOARD TRAVEL 
'I have two passions: snowboarding and traveling.'

(2) a. Cardinal ONE (attested in both younger and older signers)

(IX-1) TAKE [ONE GOLD], [TWO SILVER], [THREE BRONZE]

'I won one gold, two silver, and three bronze (medals).'

b. Determiner ONE (mainly attested in older signers)

[ONE EVENING] IX-1 CALL MOTHER

'One evening I called my mother.'

(3) a. Cardinal $>$ Measure

SOON, LEFT [TWO WEEK], IX-1 BECOME DAD IX-1

'In a short time, in two weeks, I'll be a dad.'

b. * Measure>Cardinal

* SOON, LEFT [WEEK TWO], IX-1 BECOME DAD IX-1

We also show that definiteness and contrastive focus impose restrictions in the word order flexibility found in nominal constructions. We adopt the cartographic approach to account for word order variation (Cinque 2005, 2010, 2012).

The literature on cardinals is quite vast. Issues such as the categorical specification of cardinals (for a general discussion, see Corbett 1978 and Zweig 2006), the semantic composition of complex cardinals (for a general discussion, see Ionin \& Matushansky 2006), and the morphological interaction between cardinal and noun are not addressed due to time and space limitations (for a general overview, see Hurford 2003; for a study on 
Slavic languages, see Franks 1994).

The paper is organized as follows. Section 2 summarizes what has been documented so far on the distribution of cardinals and presents an unexpected discrepancy between elicited and corpus data. Section 3 illustrates the main methodological aspects linked to the different data sources employed in the present study. Section 4 offers a description of the cardinal system in LIS and provides an overview of the formational strategies employed to express cardinality. In Section 5, we show that not all cardinals should be considered alike. Specifically, the sign ONE and cardinals included in Measure Phrases have a special morphosyntactic behavior. In Section 6, we show that the distribution of cardinals is sensitive to definiteness and contrastive focus. Section 7 provides a formal account, while Section 8 concludes the paper.

\section{BACKGROUND ON LIS CARDINALS}

This section summarizes the basic facts about the syntax of cardinals in LIS as it emerges from the most recent literature, although to our knowledge there is no systematic study on this topic. Indeed, only a few studies on other topics mention the position of cardinals in the DP in LIS. These studies are divided into two groups: those based on elicited data (Bertone 2007, Branchini 2007, Brunelli 2011, Cecchetto, Geraci \& Zucchi 2009), and the one based on corpus data (Mantovan \& Geraci 2017).

Bertone (2007, 2009), Branchini (2007), and Brunelli (2011) address the internal structure of the DP domain in LIS. The empirical base of these three studies is represented, 
to a large extent, by elicited data. The three authors substantially agree that nominal modifiers occur in postnominal position. Considering the three modifiers mentioned in Greenberg's (1963) Universal 20 (i.e., demonstrative, cardinal numeral, and adjective), the canonical DP-internal word order is claimed to be head initial, as in (4).

\section{(4) $\mathrm{N}>$ Adj $>$ Card $>$ Dem}

Cardinals behave similarly to other nominal modifiers in that they occur after the noun. This is illustrated in the examples in (5), (6), and (7).

(5) [BOOK NEW TWO IX-DEM] POSS-1

(Bertone 2007: 84)

'These two new books are mine.'

(6) [CHILDREN THREE IX-DEM] ICE-CREAM LIKE

(Branchini 2007: 50)

'These three children like ice cream.'

(7) IX-1 [BOOK THREE] EXIST

(Brunelli 2011: 61)

'I have three books.'

Bertone (2007), Branchini (2007), and Brunelli (2011) offer a stable picture in which the noun and the cardinal seem to be distributed according to rather unvarying patterns (i.e., $\mathrm{N}>$ Card). A slightly different perspective is offered by Cecchetto, Geraci \& Zucchi (2009). They claim that the order $\mathrm{N}>$ Card is the prevalent one, as exemplified in (8)a (2009: 84). 
However, the order Card $>\mathrm{N}$ is also possible, as illustrated in (8)b (2009: 84), even if such an order is employed to a lesser extent.

(8) a. [STUDENT THREE] ARRIVE DONE

b. [THREE STUDENT] ARRIVE DONE

'Three students arrived.'

In Mantovan \& Geraci (2017), the syntax of nominal expressions in LIS has been investigated through a quantitative study based on corpus data. They report that the majority of LIS modifiers (1216 tokens, 60\%) occur in postnominal position, although a considerable amount of prenominal modifiers was also found (692 tokens, 34\%) together with a marginal number of cases of repetition (115 tokens, $6 \%$ ). Focusing on the case of cardinal numerals, Mantovan and Geraci show that the order Card $>\mathrm{N}$ is the most frequent option in their corpus analysis (79\% of occurrences), contra Bertone (2007), Branchini (2007) and Brunelli (2011). The distribution of cardinals in Mantovan and Geraci's study is reported in Table $1 .^{4}$

\begin{tabular}{|c|c|c|}
\hline Word order & n & \% \\
\hline Card $>\mathrm{N}$ & 278 & 79 \\
\hline $\mathrm{N}>$ Card & 75 & 21 \\
\hline
\end{tabular}

Table 1: Distribution of cardinal numerals in corpus data (total: 353). Pearson's Chi- 
squared test: $X$-squared $=116.74, \mathrm{df}=1, \mathrm{p}$-value $<0.001 .^{5}$

The pattern that emerges from previous studies on the distribution of cardinals is thus conflicting. On the one hand, Bertone (2007), Branchini (2007) and Brunelli (2011) report that the most common or even the only possible order is $\mathrm{N}>\mathrm{Card}$. On the other hand, Cecchetto, Geraci \& Zucchi (2006) claim that both $\mathrm{N}>$ Card and Card $>\mathrm{N}$ orders are equally possible, while Mantovan and Geraci (2017) report that the Card $>\mathrm{N}$ is significantly the most frequent option in the LIS corpus.

Within this picture, our goal is first to offer a general description of how the cardinal system of LIS works (Section 4) and then to shed light on what drives the distribution of cardinals and in what respect the $\mathrm{Card}>\mathrm{N}$ order is different from the $\mathrm{N}>\mathrm{Card}$ order (Sections 5 and 6). Before that, we briefly turn to explain the research method.

\section{Methodology}

The linguistic data discussed in this paper come from several sources, namely dictionary data, spontaneous narratives included in corpus data, data elicited from a picture description task, and acceptability judgments. In this section, we briefly discuss the main methodological aspects characterizing data collection.

The general description of the cardinal system of LIS offered in Section 4 is based on data from the following LIS dictionaries: "Dizionario bilingue elementare della lingua italiana dei segni” (Radutzky 2001) and "Spread the Sign”, an online dictionary 
(www.spreadthesign.com/it, Acc. May, 2018). The data reported in the dictionaries are consistent with the LIS cardinals signed by our informants.

The data included in Section 5 are taken from the LIS corpus project (Geraci et al. 2010, Cardinaletti, Cecchetto \& Donati 2011). In this project, fluent signers from all over Italy took part into four different linguistic tasks (i.e., individual spontaneous narration, question-answer elicitation task, free conversation among three people, and picture-naming task). Here we focus on the spontaneous narratives produced by 162 signers coming from ten Italian cities, ranging from age 18 to 81 , and with different familial and educational backgrounds. In this specific task, participants were encouraged to talk about their personal experiences connected with education, family, job, etc.

In section 6 , we discuss data elicited from a picture description task and acceptability judgments. These data come from three Deaf native LIS signers. Details about their linguistic and demographic background are provided in Table 2.

\begin{tabular}{|c|c|c|c|}
\hline & Informant 1 & Informant 2 & Informant 3 \\
\hline Gender & $\mathrm{M}$ & $\mathrm{F}$ & $\mathrm{M}$ \\
\hline Age & 33 & 46 & 37 \\
\hline Geographical origin & $\begin{array}{c}\text { Campania } \\
\text { (Southern Italy) }\end{array}$ & $\begin{array}{c}\text { Lombardy } \\
\text { (Northern Italy) }\end{array}$ & $\begin{array}{c}\text { Sicily } \\
\text { (Southern Italy) }\end{array}$ \\
\hline Parental hearing status & Deaf & Deaf & Deaf \\
\hline Age of LIS exposure & Birth & Birth & Birth \\
\hline Education & University & High School & University \\
\hline
\end{tabular}

Table 2: Linguistic and demographic background of the informants. 
In order to have a more controlled but still relatively natural environment, we engaged our informants in a picture-based narrative task. The picture story is reproduced in Figure 1 (Ohser 2000).
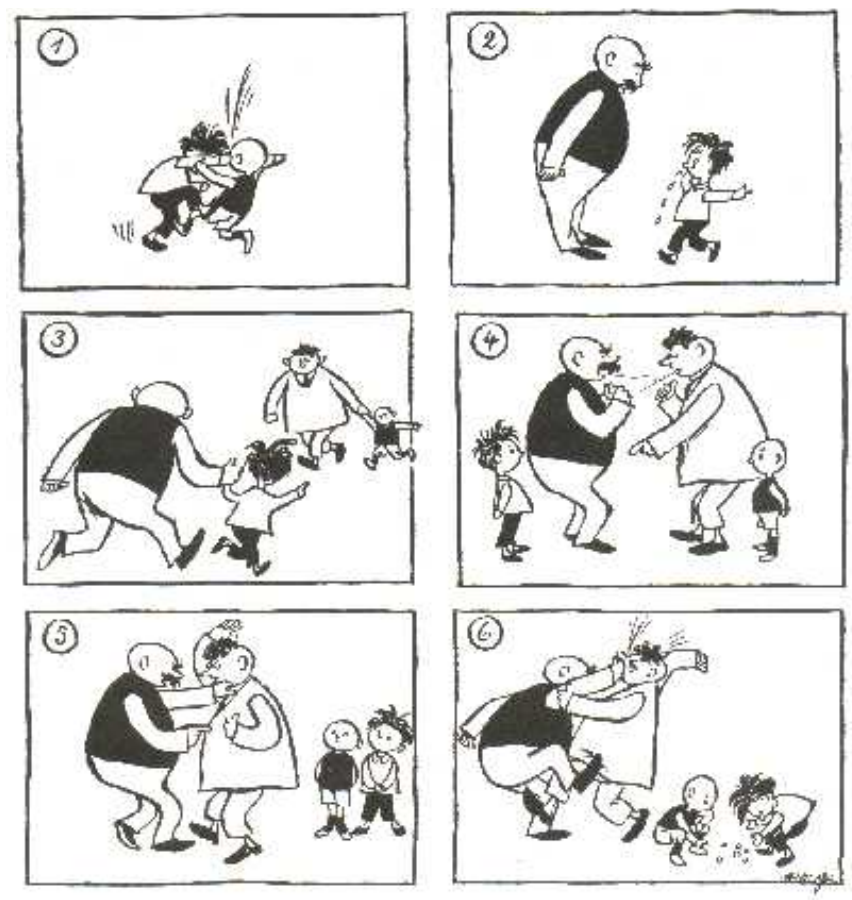

Figure 1: Extract from "Vater und Sohn" (Ohser 2000).

This task has proven to be useful to identify the role of definiteness in determining word order preferences. The story is self-explanatory and does not contain any written text. Our specific interest was to observe how cardinal TwO was produced in the first and in the fifth 
(or sixth) panel. Indeed, in the first panel, two children are represented for the very first time. Being first-mentioned referents, they are expected to be introduced in the discourse by an indefinite nominal expression (e.g., 'two children were fighting on the street'). However, the two children represented in the fifth panel are pre-established referents (they are the same two children of the first panel), therefore they are expected to be referred to by using a definite nominal expression (e.g., 'the two children were looking at their fathers'). The production of the signers has been annotated using ELAN (Johnston \& Crasborn 2006). Manual markers and non-manual markers (NMMs) have been carefully annotated on separate tiers. The NMMs relevant to this study are head position (left, right, raised, down, forward, back), body posture (left, right, down, forward, back), eyebrows (lowered, raised), and eyes (blink, squint, close, wide, trackhands eye-gaze).

Finally, acceptability and felicity judgments were elicited to verify fine-grained hypotheses about the structure of Measure Phrases and collect preliminary information about the effect of specificity and various kinds of focus on the distribution of cardinals.

\section{ON THE CARDINAL SYSTEM OF LIS}

The cardinal system of LIS involves the use of both hands and is a base-10 system. Typologically, both spoken and sign languages show a preference in using 10 as numeral base (Zeshan, Escobedo Delgado, Dikyuva, Panda \& De Vos 2013). This preference is clearly linked to the anatomical configuration of human hands and verbal counting has very often its origin in manual counting (Hanke 2010: 72). 
In LIS, cardinals from 1 to 10 are realized by extending the corresponding number of fingers, as shown by the handshapes reported in Figure $2 .{ }^{6}$

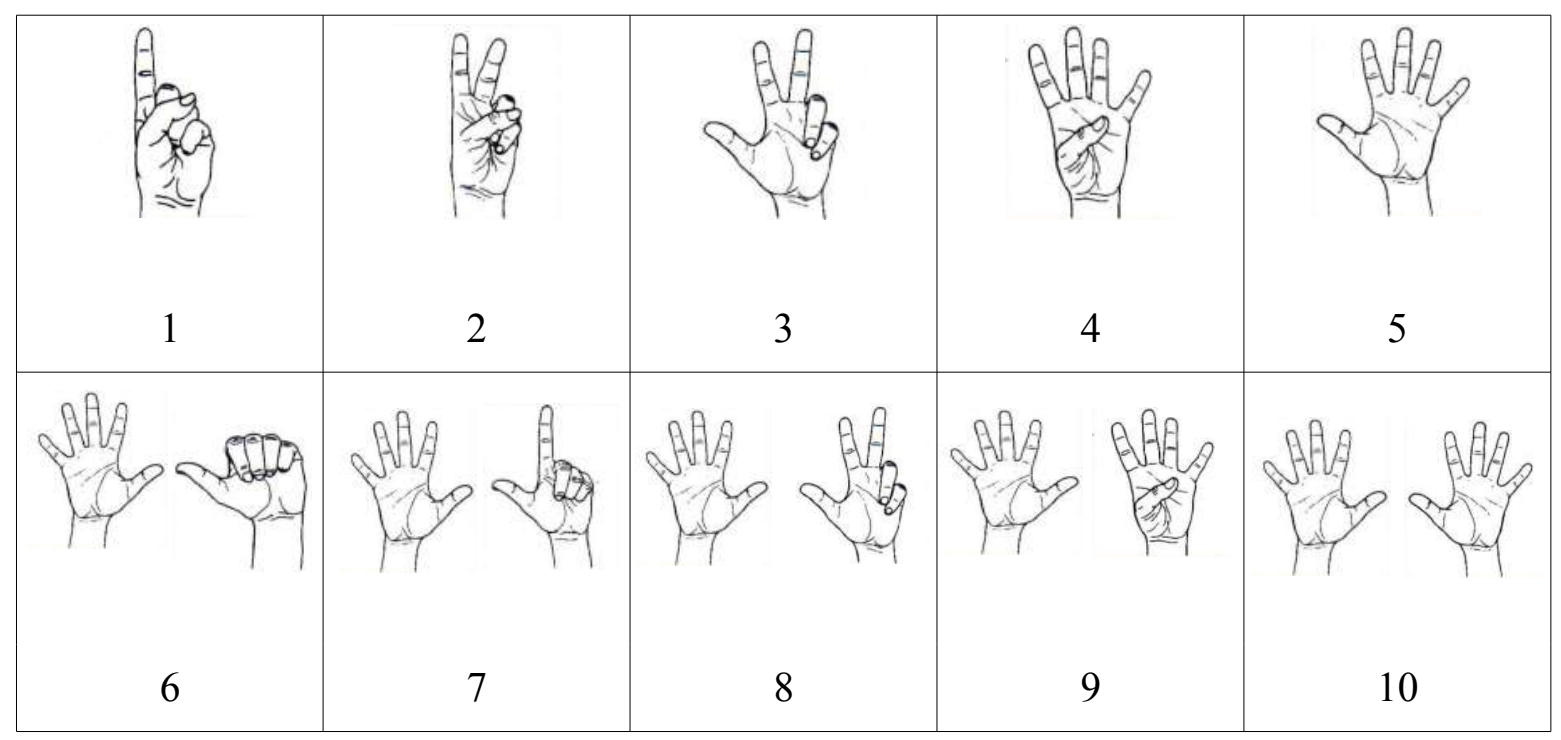

Figure 2: LIS cardinals from 1 to 10.

Note that variation is attested at some degree. Specifically, some LIS signers produce the sign ONE by extending the thumb (extended-A handshape) instead of the index finger (1 handshape), ${ }^{7}$ and produce the sign TwO by extending thumb and index finger (L handshape) instead of index and middle finger (V handshape). These two alternatives (i.e., extended-A and L handshapes) are obligatorily articulated by the dominant hand in cardinals SIX and SEVEN, respectively. Notice also that from 6 to 10, the non-dominant hand always realizes the 5 handshape. ${ }^{8}$

Crosslinguistic data suggest that the formation of complex cardinals capitalizes on basic 
arithmetic operations (Hurford 2003). ${ }^{9}$ Zeshan et al. (2013) show that these operations are applied to construct complex cardinals in the visual modality, too. The authors propose a typological classification accounting for the main formational strategies commonly adopted to express cardinality in the world's sign languages. It includes the following strategies: multiplicative, additive, subtractive, digital, and spatial modification. Applying Zeshan et al.'s (2013) classification to LIS complex cardinals, three formational strategies emerge: i) multiplicative, ii) digital, and iii) additive.

The multiplicative strategy simultaneously combines digit handshapes with particular hand or wrist movements. This strategy is used in LIS to express tens, hundreds, and thousands. These three groups of cardinals are all produced with outward palm orientation (i.e., the palm(s) is/are oriented away from the signer) and can be distinguished by movement type. Tens combine handshapes from 2 to 9 with finger bending. In some cases (e.g., FORTY), there are two possibilities: bending all fingers or bending the index finger only. ${ }^{10}$ Thousands combine handshapes from 1 to 10 with downward wrist flexion. This is exemplified in Figure 3a (Radutzky 2001: fig. 352.1), which represents the sign THREETHOUSAND. The movement employed in hundreds is a more complex one because it involves an outward shift toward the ipsilateral side of the signing space and simultaneous finger bending. The sign THREE-HUNDRED represented in Figure $3 b$ (Radutzky 2001: fig. 346.2) is an illustrative example. 


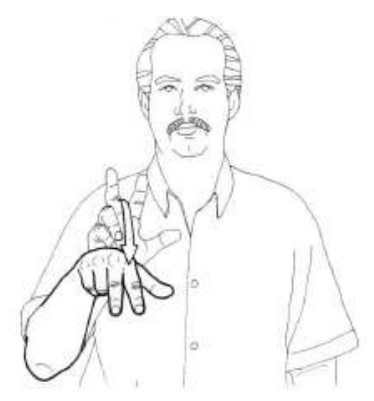

(a) THREE-THOUSAND

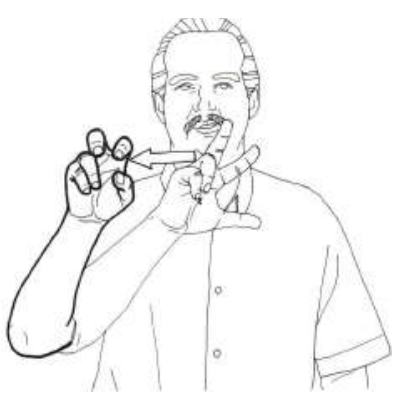

(b) THREE-HUNDRED

Figure 3: LIS signs THREE-THOUSAND and THREE-HUNDRED (multiplicative strategy).

The digital strategy is used for cardinals from 21 to 99 (with the exclusion of tens). It consists in sequentially producing individual digits following the order in which they appear in writing. For example, the sign THIRTY-FOUR is realized by juxtaposing THREE and FOUR, as illustrated in Figure 4. The transitional movement from one sign to the other may involve a slight outward shift toward the ipsilateral side of the signing space (especially when the two digits are identical, e.g., 33).

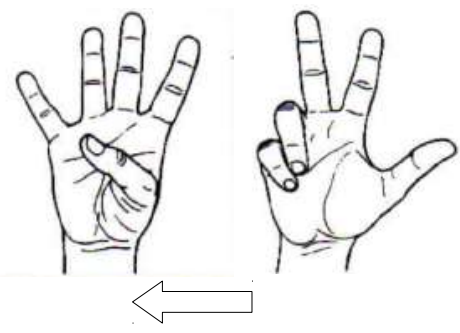

Figure 4: LIS sign THIRTY-FOUR (digital strategy). 
Finally, the additive strategy is used for cardinals above 100. This strategy combines two or more signs, the sum of which equals the quantity expressed by the cardinal. The signs are sequentially arranged one after the other and are not linked by any overt conjunction. This can be seen as a case of asyndetic coordination (Ionin \& Matushansky 2006). To illustrate this formational strategy, we consider the sign for 3409. It is formed by three signs ordered from the highest to the lowest: THREE-THOUSAND, followed by FOUR-HUNDRED, followed by NINE.

A special case concerns cardinals from 11 to 19 . In the most widespread variants, digit handshapes are combined with wrist movements. In cardinals from 11 to 15 , handshapes from 1 to 5 realized with contralateral palm orientation are associated with a repeated downward twist of the wrist on the sagittal plane. Cardinals from 16 to 19 are similarly produced except that the palm orientation is toward the signer and the repeated downward twist of the wrist is on the vertical plane. This group of cardinals are structurally complex and cannot straightforwardly be analyzed within any of the strategies included in Zeshan et al.'s (2013) classification. The repeated movement characterizing these cardinals suggests the presence of an additional morpheme, thus a morphological process is likely to be involved. ${ }^{11}$

Like many other sign languages, LIS allows for numeral incorporation. This is a morphological process that incorporates the cardinal handshape into a sign. The signs that can be combined with cardinals are plural personal pronouns (e.g., IX-2_PL, IX-3_PL), nouns 
referring to time (e.g., MONTH, YEAR, HOUR), and a few other signs (e.g., FLOOR, MARK). The cardinals that can be incorporated are either from 1 to 5 (e.g., with the sign DAY) or from 1 to 10 (e.g., with the sign MONTH). From 1 to 5, numeral incorporation involves the dominant hand only, while from 6 to 10, it involves both hands. The combination of a cardinal and a noun referring to time is discussed from a syntactic perspective in Section 7.2 .

Although ordinal numerals in LIS are not under investigation in this paper, it is worth mentioning that they constitute a defective class since they are a limited series of ten items, from 1st to 10th. From a phonological point of view, they share the same handshapes and location as their cardinal counterparts (see Figure 2), while movement and hand orientation vary according to the kind of entity the ordinals refer to (e.g., sequences, winning positions, railway platforms, house floors).

\section{ON THE DISTRIBUTION OF CARDINALS IN LIS}

Although Mantovan and Geraci (2017) showed that overall the majority of cardinals occur in prenominal position in the LIS corpus (see Section 2 above), a deeper analysis of their data combined with new data collected in this study provide evidence that not all occurrences of cardinals in the corpus should be treated alike. Indeed, we found two exceptional cases: i) the sign ONE, which is potentially ambiguous between cardinal and indefinite determiner (cf. Borer 2005 for the proposal to treat one differently from other cardinals in Hebrew), and ii) cardinals included in Measure Phrases (e.g., THREE WEEK, 
henceforth MPs), which are only found in prenominal position (cf. Corver 2009 for a discussion on the syntactic peculiarities of this construction).

Because of their special nature, these cases are treated separately in Sections 5.1 and 5.2, respectively. Interestingly, once the two exceptional cases are removed from the picture, the distribution of cardinals becomes even more puzzling in that pre- and post-nominal cardinals have a virtually identical distribution. As a preview to the discussion in Section 6, Table 3 shows the distribution of the data.

\begin{tabular}{|c|c|c|c|c|c|c|}
\hline \multirow{2}{*}{$\begin{array}{c}\text { Word } \\
\text { order }\end{array}$} & $\begin{array}{c}\text { coneral } \\
\text { distribution } \\
\text { (total: 353) }\end{array}$ & \multicolumn{2}{|c|}{$\begin{array}{c}\text { Distribution without } \\
\text { determiner ONE and } \\
\text { ambiguous cases (total: 295) }\end{array}$} & \multicolumn{2}{|c|}{$\begin{array}{c}\text { Distribution without } \\
\text { determiner ONE, ambiguous } \\
\text { cases and MPs (total: 155) }\end{array}$} \\
\cline { 2 - 7 } & $\mathbf{n}$ & $\mathbf{\%}$ & $\mathbf{n}$ & $\mathbf{\%}$ & $\mathbf{n}$ & \% \\
\hline Card $>\mathrm{N}$ & 278 & 79 & 220 & 75 & 80 & 52 \\
\hline $\mathrm{N}>$ Card & 75 & 21 & 75 & 25 & 75 & 48 \\
\hline
\end{tabular}

Table 3: Distribution of cardinals without the two confounders.

In the first column, we report the overall distribution of cardinals in corpus data. In the second column, we report the distribution without cases where ONE is clearly used as a determiner and cases where ONE is ambiguous between a determiner and a cardinal. In the last column, we further excluded cardinals included in MPs.

\subsection{The case of ONE}

Careful inspection of corpus data revealed that the sign ONE is ambiguous between a 
cardinal and an indefinite determiner reading. The examples below illustrate the two functions. In (9), ONE qualifies as cardinal because it indicates how many steps the king piece can move in a chess game. In (10), ONE qualifies as indefinite determiner because it does not quantify over anything, rather it introduces a first-mentioned referent (TOWN).

(9) KING ONE STEP ONE CL $[\ldots]$ ONE STEP [older signer from Rome]

'The king moves one step at a time, one step.'

(10) IX-1 BE-BORN ONE TOWN IX $\mathrm{X}_{\mathrm{i}}$ PROVINCE PERUGIA IX $\mathrm{X}_{\mathrm{i}} \quad$ [older signer from Florence] 'I was born in a town in the province of Perugia.'

In both cases, the context is crucial in order to detect the status of ONE and understand its meaning. However, in the corpus, we also found cases where it was impossible to adjudicate the correct function of the sign ONE. One example is given in (11), where it is not clear whether ONE is used to denote a quantity or introduce a new referent.

(11)

THERE-IS ONE DEAF THERE-IS, MEET

[middle-aged signer form Rome] 'I met a/one deaf person.'

Because of this dual status, the sign ONE has a completely different frequency with respect to the other cardinals, as shown in Table 4. 


\begin{tabular}{|c|c|c|}
\hline Gloss & $\mathbf{n}$ & $\mathbf{\%}$ \\
\hline ONE & 101 & 29 \\
\hline TWO & 49 & 14 \\
\hline THREE & 32 & 9 \\
\hline FOUR & 13 & 4 \\
\hline FIVE & 16 & 5 \\
\hline SIX & 9 & 3 \\
\hline
\end{tabular}

Table 4: The six most frequent cardinals in the corpus (220/353).

The sign ONE is by far the most frequent item with 101 occurrences (out of 353 annotated cardinals), twice more than the second most frequent cardinal (TWO) (Pearson's Chisquared test: $\mathrm{X}$-squared $=18.29, \mathrm{p}$-value $<.001)$. This huge discrepancy can be easily accounted for by arguing that ONE is ambiguous between a cardinal and an indefinite determiner (as reported for 112 languages out of 534 in the WALS database, Dryer 2013).

The different semantic status of ONE (cardinal vs. determiner) in LIS is also reflected in the syntax. The data in Table 5 show that ONE significantly appears before the noun $(92 \%$, $\mathrm{X}$-Square $=71.5, \mathrm{p}<.001)$. However, when used as determiner, ONE never appears in postnominal position in our corpus. The distribution of cardinal ONE is predominantly prenominal ( $81 \%$ in prenominal and $19 \%$ in postnominal position). It is important to note that this group of tokens includes 19 cases of cardinal ONE contained in MPs (e.g., ONE LITER). In this construction, cardinals show a categorical distribution as they always occur in prenominal position (cf. Section 5.2). Once these 19 tokens are discarded, the remaining 24 cases of cardinal ONE still show a predominantly prenominal distribution: 16 tokens 
$(66 \%)$ appear before the noun and 8 tokens (33\%) appear after the noun.

\begin{tabular}{|c|c|c|c|c|c|c|c|c|}
\hline & \multicolumn{2}{|c|}{$\begin{array}{c}\text { Determiner ONE } \\
\text { (total: 23) }\end{array}$} & \multicolumn{2}{|c|}{$\begin{array}{c}\text { Cardinal ONE } \\
\text { (total: 43) }\end{array}$} & $\begin{array}{c}\text { Ambiguous cases } \\
\text { (total: 35) }\end{array}$ & \multicolumn{2}{c|}{$\begin{array}{c}\text { Tot. } \\
\text { (total: 101) }\end{array}$} \\
\hline Word order & $\mathbf{n}$ & $\mathbf{\%}$ & $\mathbf{n}$ & $\mathbf{\%}$ & $\mathbf{n}$ & $\%$ & $\mathbf{n}$ & $\%$ \\
\hline ONE $>$ N & 23 & 100 & 35 & 81 & 35 & 100 & 93 & 92 \\
\hline $\mathrm{N}>\mathrm{ONE}$ & 0 & 0 & 8 & 19 & 0 & 0 & 8 & 8 \\
\hline
\end{tabular}

Table 5: Distribution of ONE in corpus data.

An anonymous reviewer suggested that the strong prenominal preference of cardinal ONE might be explained in terms of definiteness. As we will see in Section 6.1, definite cardinals in LIS require the $\mathrm{N}>\mathrm{Card}$ order. Our corpus data, in which there is an overall preference for cardinal ONE in prenominal position, is in line with the more general fact that the cardinal one is unlikely to be used with a definite interpretation (e.g., in English, a phrase such as 'the one cat' is rarely used, relative to 'the two cats', and is only possible with focus on one).

The behavior of the sign ONE becomes even more interesting once we look at its distribution by age group. Signers participating in the LIS corpus project have been divided into three age groups. This classification reflects the historical evolution of education policies in Italy: older signers (over the age of 55) attended (residential) schools for the deaf, middle-aged signers (from 31 to 54) were in the middle of the transition from the Deaf school system to mainstream education, and the majority of younger signers (from 18 
to 30) attended mainstream schools (Geraci et al. 2011). Table 6 shows the distribution of cardinals from 1 to 6 by the three age groups.

\begin{tabular}{|c|c|c|c|c|c|c|}
\hline \multirow{2}{*}{ Gloss } & \multicolumn{2}{|c|}{$\begin{array}{c}\text { Older signers } \\
\text { (total: 144 cardinals) }\end{array}$} & \multicolumn{2}{c|}{$\begin{array}{c}\text { Middle-aged signers } \\
\text { (total: 131 cardinals) }\end{array}$} & \multicolumn{2}{c|}{$\begin{array}{c}\text { Younger signers } \\
\text { (total: 78 cardinals) }\end{array}$} \\
\cline { 2 - 7 } & $\mathbf{n}$ & $\mathbf{\%}$ & $\mathbf{n}$ & $\mathbf{\%}$ & $\mathbf{n}$ & $\%$ \\
\hline ONE & 45 & 31 & 41 & 31 & 15 & 19 \\
\hline TWO & 15 & 10 & 19 & 15 & 15 & 19 \\
\hline THREE & 11 & 8 & 12 & 9 & 9 & 12 \\
\hline FOUR & 7 & 5 & 3 & 2 & 3 & 4 \\
\hline FIVE & 7 & 5 & 6 & 5 & 3 & 4 \\
\hline SIX & 3 & 2 & 4 & 3 & 2 & 3 \\
\hline
\end{tabular}

Table 6: Frequency data of cardinals according to signers' age group.

Cardinals from 2 to 6 occur with similar frequency across the three age groups. The main difference concerns the distribution of the sign ONE. Older and middle-aged signers produce it more frequently than younger signers $(31 \%$ of the total number of cardinals, as opposed to $19 \%$ ). We compared the occurrences of ONE and TWO (i.e., the two most frequent items) with respect to the variable Age group (older vs. younger signers). The analysis revealed that there is a significant difference between the groups of older and middle-aged signers and the group of younger signers $(X$-squared test $=4.55, \mathrm{df}=1, \mathrm{p}$-value $=.03)$.

Focusing on the semantic functions of ONE, Table 7 reports the distribution of determiner vs. cardinal uses for unambiguous cases, cf. examples (9) and (10) above. 


\begin{tabular}{|c|c|c|c|c|c|c|}
\hline \multirow{2}{*}{} & \multicolumn{2}{|c|}{$\begin{array}{c}\text { Older signers } \\
\text { (total: 45) }\end{array}$} & $\begin{array}{c}\text { Middle-aged signers } \\
\text { (total: 41) }\end{array}$ & \multicolumn{2}{c|}{$\begin{array}{c}\text { Younger signers } \\
\text { (total: 15) }\end{array}$} \\
\cline { 2 - 7 } & $\mathbf{n}$ & $\mathbf{\%}$ & $\mathbf{n}$ & $\mathbf{\%}$ & $\mathbf{n}$ & $\%$ \\
\hline Determiner ONE & 12 & 27 & 10 & 24 & 1 & 6 \\
\hline Cardinal ONE & 16 & 35 & 17 & 42 & 10 & 67 \\
\hline Ambiguous status & 17 & 38 & 14 & 34 & 4 & 27 \\
\hline
\end{tabular}

Table 7: Instances of ONE in the three age groups.

In the older and middle-aged signers, the pattern is very similar to what happens in Italian, where the words un/uno/un'/una are ambiguous between the cardinal and the determiner reading. As for younger signers, ONE is almost exclusively used as cardinal. ${ }^{12}$ We can speculate that ONE has evolved from being ambiguous between determiner and cardinal to the status of pure cardinal. This process seems to be almost completed as occurrences of determiner ONE are virtually absent in the production of the younger signers of LIS corpus (this fact also explains why we have fewer ambiguous cases) and none of our informants uses ONE as a determiner.

One possible explanation for this diachronic effect is that some form of sociolinguistic pressure is at play. Nowadays, there is generally more awareness of LIS as an independent linguistic system (Geraci 2012) and this is reflected in the education policy with the gradual disuse of mixed forms of communication like Signed Italian (Mantovan, Duarte, Geraci \& Cardinaletti 2016). We speculate that younger signers, being more aware of the linguistic 
status of LIS, unconsciously perceive the ambiguous status of ONE as a direct influence of Italian, and hence a non-genuine pattern. A comparable process has been documented in younger speakers of Sipakapense (i.e., a Mayan language), who avoid SVO order because they perceive it as a direct influence from Spanish, the language spoken by colonialists, even in linguistic contexts where old Mayan allows SVO (Barrett 2008).

If the use of ONE as indefinite determiner has been reduced over generations, younger signers are expected to express indefinite nominal expressions through other linguistic means. This seems to be the case. In particular, indefinite NPs are produced with a facial expression denoting uncertainty, which consists in pulling the corners of the mouth down (Mantovan and Geraci, submitted). This can be combined with a shrug, as similarly reported for Catalan Sign Language (LSC) (see Barberà 2012: 237).

In some cases, it is possible to disambiguate the function of ONE by examining subtle phonological cues. As illustrated in Figure 5, cardinal ONE is usually associated with neutral NMMs (i.e., head and eyebrows in neutral position). Determiner ONE often co-occurs with some NMMs, such as backward-tilted head and slightly raised eyebrows (see Figure 6). These NMMs are often used to convey indefiniteness (this aspect is further discussed in Section 6.1). 


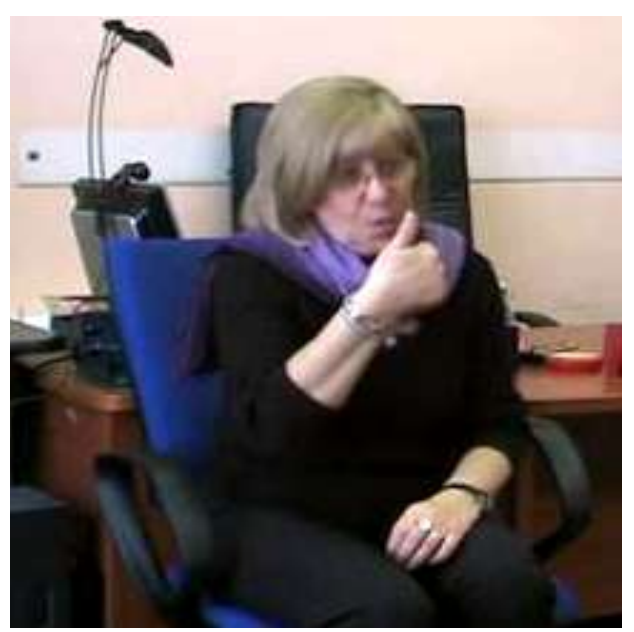

Figure 5: NMMs associated with cardinal ONE.

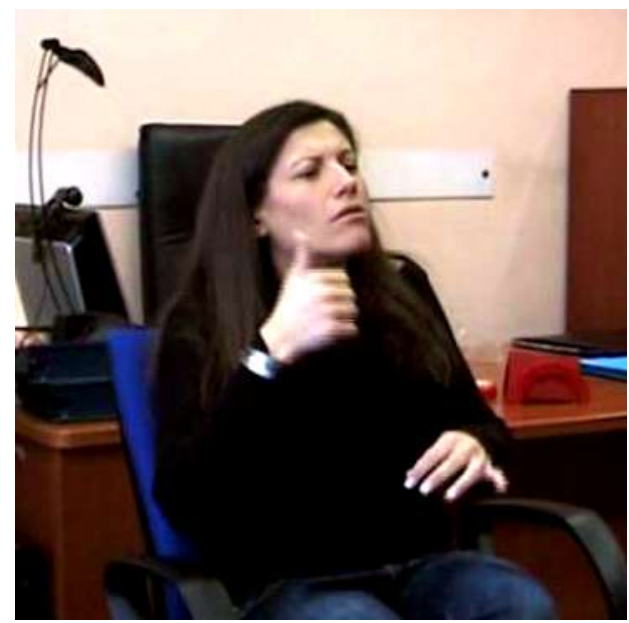

Figure 6: NMMs associated with determiner ONE.

Palm orientation may also provide cues to disambiguate the two uses of ONE. Specifically, cardinal ONE is usually articulated with the palm facing the signer (cf. Figure 5). This happens in 32 occurrences out of the 43 clear instances of cardinal ONE in the corpus $(74 \%)$. The difference is statistically significant $(\mathrm{X}$-square $=10.256, \mathrm{p}=.002) .{ }^{13}$ Note that this pattern is similar to the one discussed for Hong Kong Sign Language (Tang \& Sze 2002). In contrast, determiner ONE is usually produced with contralateral palm orientation (cf. Figure 6). This happens in 15 occurrences out of the 23 clear instances of determiner ONE in the corpus (65\%). ${ }^{14}$ Apparent counterexamples in our corpus data can be explained in terms of phonological assimilation. ${ }^{15}$ 
Corpus data also revealed another interesting phonological difference: ONE can be realized either with extended thumb (56 occurrences) or extended index finger (45 occurrences). The two handshapes are shown in Figure 7 and Figure 8, respectively.

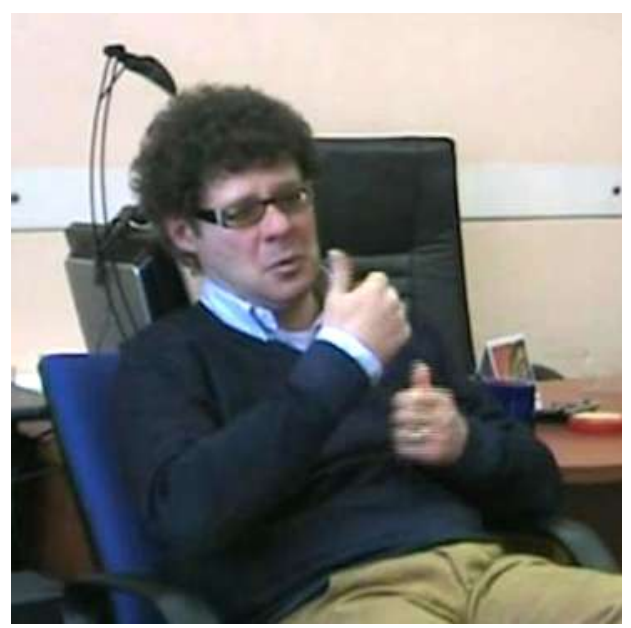

Figure 7: ONE with extended thumb [Middle-aged signer from Turin].

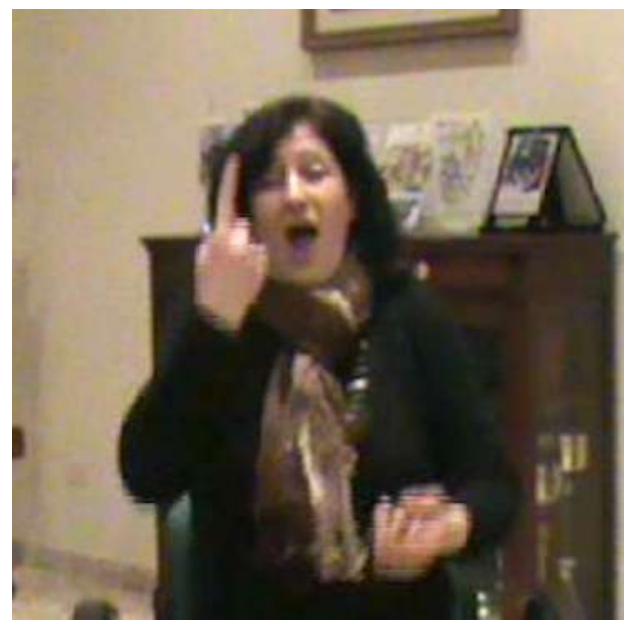

Figure 8: ONE with extended index finger [Middle-aged signer from Salerno].

These options do not show any correlation with the functions of cardinal and determiner.

This handshape variation is influenced by geographical factors. The extended index finger version of ONE is preferred by Southern signers, whereas the extended thumb variant is more common in the North. Signers from Central Italy tend to use both hand configurations, as shown in Table $8 .^{16}$ 


\begin{tabular}{|l|c|c|c|c|}
\hline \multirow{2}{*}{ Signers' place of residence } & \multicolumn{2}{|c|}{ Extended thumb } & \multicolumn{2}{c|}{ Extended index finger } \\
\cline { 2 - 5 } & $\mathbf{n}$ & $\mathbf{\%}$ & $\mathbf{n}$ & $\%$ \\
\hline $\begin{array}{l}\text { Northern Italy (Turin, Milan, Brescia, } \\
\text { Bologna), total: } 51\end{array}$ & 44 & 86 & 7 & 14 \\
\hline $\begin{array}{l}\text { Central Italy (Florence, Rome), total: } \\
24\end{array}$ & 9 & 37.5 & 15 & 62.5 \\
\hline $\begin{array}{l}\text { Southern Italy (Trani, Salerno, } \\
\text { Lamezia, Ragusa), total: } 26\end{array}$ & 3 & 12 & 23 & 88 \\
\hline
\end{tabular}

Table 8: Variation of the handshape of ONE according to signers' place of residence.

In summary, the sign ONE is subject to both regional and diachronic variation. Variation in handshape (index vs. thumb extension) distinguishes between Northern vs. Non-northern varieties. Younger signers use ONE almost exclusively as a cardinal, while older signers can use it both as indefinite determiner and cardinal. In the latter population, word order, hand orientation, facial expression, and the linguistic context may help disambiguate the relevant semantic functions.

\subsection{Measure Phrases}

MPs are the other case that requires special attention. This construction represents a considerable portion of the cardinals in the corpus (140 out of 353 cardinals, $40 \%$ ). The nouns that occur in MPs are measure nouns referring to time, capacity, weight, length, temperature, and currency. Some examples are provided below. 
(12) a. WEEK TRUE [THIRTY-SIX HOUR] IX-1

[younger signer from Bologna] 'I actually work thirty-six hours per week.'

b. HOUSE CLOSE [FOUR-HUNDRED METER] [older signer from Florence]

'Our house is close by, four hundred meter away.'

c. IX-1 SLIM WEIGHT [SEVENTY KILOGRAM] [older signer from Milan]

'I was slim, my weight was seventy kilograms.'

The distribution of cardinals with respect to measure nouns is illustrated in Table 9. In MPs, the cardinal always precedes the measure noun. Orders in which the cardinal follows the measure noun are unattested. 


\begin{tabular}{|c|c|c|c|}
\hline Measure noun & Card $>\mathbf{N}$ & N $>$ Card & Example \\
\hline YEAR & 77 & 0 & TWO YEAR \\
\hline MONTH & 13 & 0 & ELEVEN MONTH \\
\hline WEEK & 10 & 0 & THREE WEEK \\
\hline DAY & 17 & 0 & FIVE DAY \\
\hline EVENING & 1 & 0 & ONE EVENING \\
\hline HOUR & 4 & 0 & SEVEN HOUR \\
\hline MINUTE & 4 & 0 & FIVE MINUTE \\
\hline SECOND & 1 & 0 & FIVE SECOND \\
\hline TIME/INSTANCE & 2 & 0 & THREE TIME \\
\hline KILOGRAM & 1 & 0 & SEVENTY KILOGRAM \\
\hline LITER & 2 & 0 & ONE LITER \\
\hline BARREL & 1 & 0 & SEVEN BARREL \\
\hline KILOMETER & 2 & 0 & THIRTY KILOMETER \\
\hline METER & 2 & 0 & FOUR-HUNDRED METER \\
\hline CREDIT & 1 & 0 & SIXTY CREDIT \\
\hline LIRA & 1 & 0 & FIFTEEN-THOUSAND LIRA \\
\hline DEGREE & 1 & 0 & FORTY DEGREE \\
\hline Total & $140 / 140$ & $0 / 140$ & \\
\hline
\end{tabular}

Table 9: Distribution of cardinals included in MPs.

Care must be taken not to assume that what is unattested in a corpus is simply ungrammatical. The fact that postnominal cardinals have not been found does not necessarily mean that the order $\mathrm{N}>$ Card is ungrammatical in MPs. However, our informants confirmed that cardinals included in MPs cannot follow the measure noun. As shown by the contrast in (13), only the option Card $>\mathrm{N}$ is acceptable. 
(13) a. IX-1 REPEAT++ TWO-HUNDRED-THOUSAND TIME

'I repeated it two-hundred-thousand times.'

b. * IX-1 REPEAT++ TIME TWO-HUNDRED-THOUSAND

The fact that cardinals contained in MPs show a categorical distribution (i.e., they only occur before the noun) indicates that this subset of cardinals has an independent behavior from that of the other cardinals. This fact calls for an independent and possibly principled explanation, an issue that we address in Section 7.2, devoted to the syntactic analysis.

6. ON THE SIGN ORDER OF CARDINAL AND NOMINAL HEAD

Once the tokens of MPs, determiner ONE, and cases in which the determiner/cardinal ambiguity of ONE could not be solved have been removed from the data, the distribution of cardinals in the corpus reveals a balanced situation, as illustrated in Table 10.

\begin{tabular}{|c|c|c|}
\hline \multirow{2}{*}{ Word order } & \multicolumn{2}{|c|}{$\begin{array}{l}\text { Distribution without determiner ONE, } \\
\text { ambiguous cases and MPs (total: 155) }\end{array}$} \\
\cline { 2 - 3 } & $\mathbf{n}$ & \% \\
\hline $\mathrm{Card}>\mathrm{N}$ & 80 & 52 \\
\hline $\mathrm{N}>\mathrm{Card}$ & 75 & 48 \\
\hline
\end{tabular}

Table 10: Distribution of cardinals without the two confounders. 
We checked whether word order is influenced by the quantity expressed by the cardinals. As Corbett (1978: 365) reported, this correlation is found in Yoruba, where cardinals up to 19 occur in postnominal position (like adjectives), whereas cardinals from 20 upwards occur in prenominal position. Our data do not show any effect of numerical gradation on word order since prenominal cardinals range from ONE to ONE-THOUSAND and postnominal cardinals range from ONE to FOUR-HUNDRED.

In Sections 6.1 and 6.2, we investigate to what extent it is possible to account for the distribution of cardinals in terms of definiteness, specificity, and focus.

\subsection{Definite vs. indefinite interpretation}

The data collected through the picture-based narrative task (see Section 3) reveal that the position of cardinals is partially influenced by information structure. When the children are first mentioned (see first panel in Figure 1), both orders (Card $>\mathrm{N}$ and $\mathrm{N}>$ Card) are possible, while in further mentions (see fifth and sixth panels in Figure 1), only the $\mathrm{N}>$ Card order is attested. This suggests that new-discourse information (i.e., indefinite, first-mentioned referents) is compatible with both orders, whereas old-discourse information (i.e., definite, already-mentioned referents) is compatible with postnominal cardinals only. This is confirmed by our informants. Both sign order options are accepted in indefinite nominal expressions, as shown in (14), whereas only the $\mathrm{N}>$ Card order is accepted in definite nominal expressions, as shown in (15). 
(14) Indefinite nominal expressions (new-information context, cf. first panel in Figure 1)
a. TWO CHILD
b. CHILD TWO

'Two children'

(15) Definite nominal expressions (old-information context, cf. fifth panel in Figure 1)
a. * TWO CHILD
b. CHILD TWO

'The two children'

The relative order of the cardinal with respect to the noun only partially depends on the discourse functions, as both new and old information can be conveyed by the $\mathrm{N}>\mathrm{Card}$ order. In these cases, NMMs may provide additional and independent cues. When the signer is dealing with a new referent, the prenominal or postnominal cardinal is accompanied by backward-tilted head and raised eyebrows (see Figure 9). When the referent has already been mentioned in the discourse, then the postnominal cardinal is accompanied by squinted eyes, lowered eyebrows, and chin down (see Figure 10). 

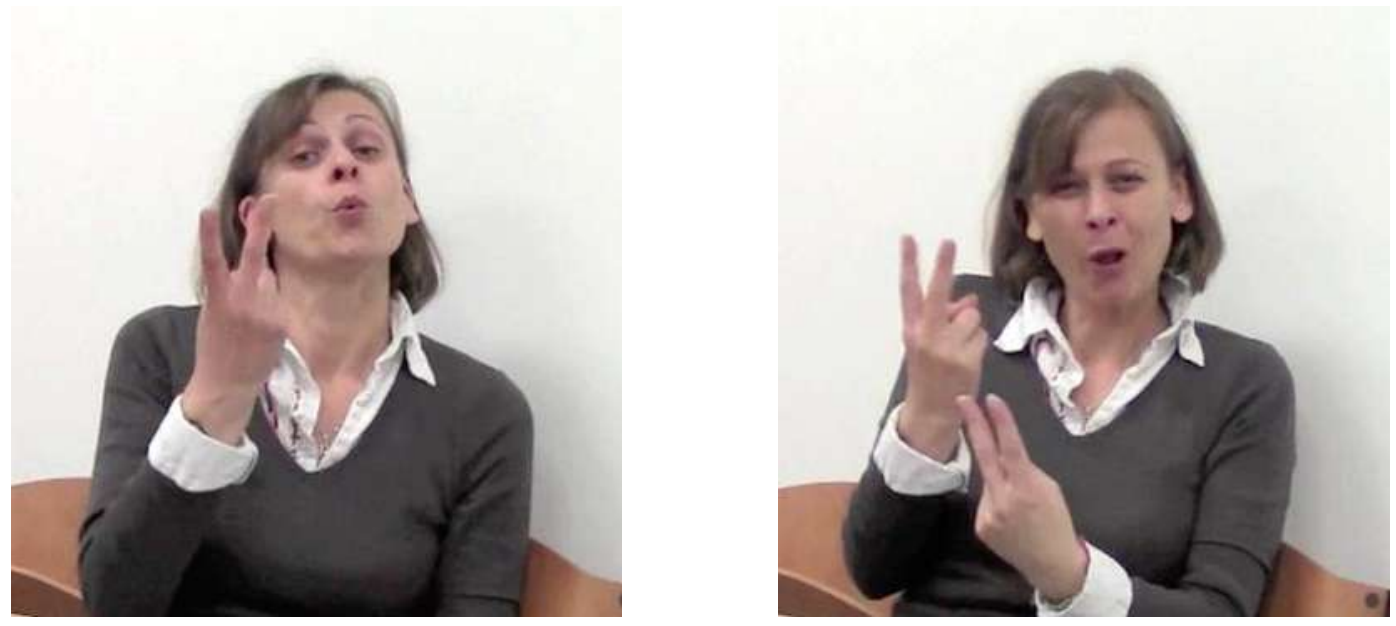

Figure 9: TWO as new-discourse information. Figure 10: TWO as old-discourse information.

Another way that our informants employed to disambiguate old vs. new information in the case of $\mathrm{N}>\mathrm{Card}$ order is by means of classifier signs. ${ }^{17}$ The relevant example is given in (16); the two classifiers that can been used in this construction are shown in Figure 11. Both of them are whole-entity classifiers indicating the referents' location in space. ${ }^{18}$

(16) $\mathrm{N}>$ Card $>$ CL (only in definite nominal expressions)

CHILD TWO CL:WHOLE-ENTITY LOOK

'The two children were looking (at their fathers).' 

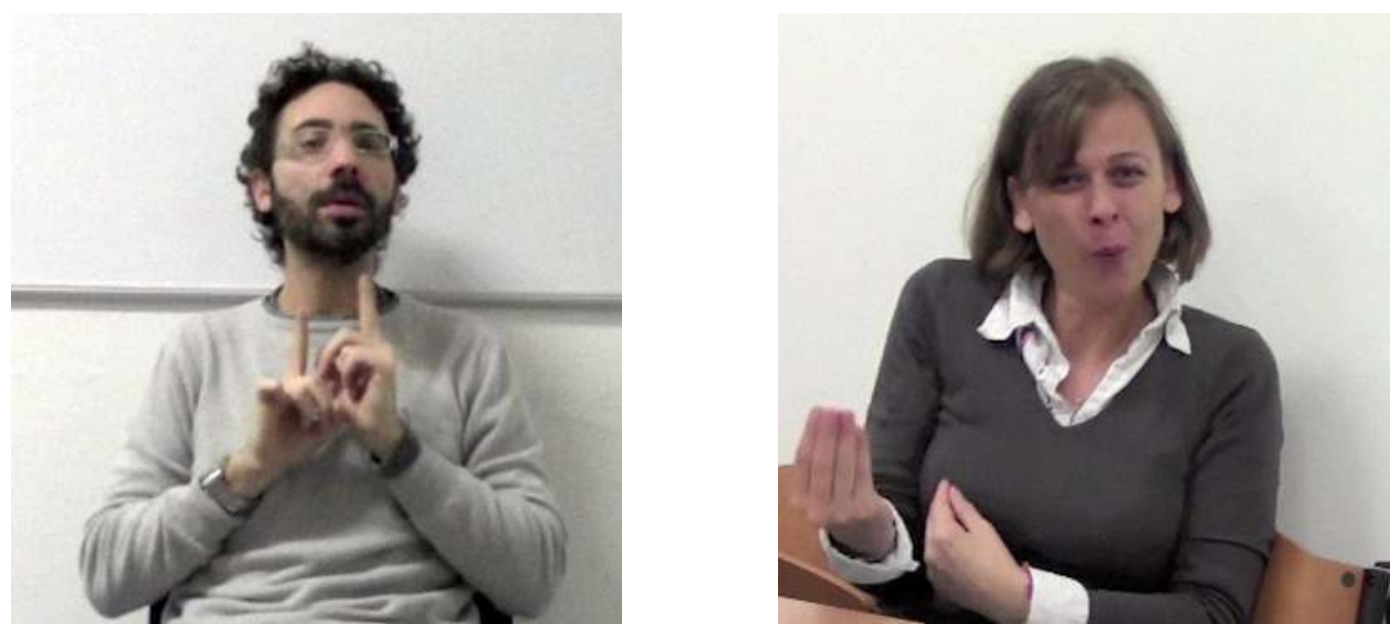

Figure 11: Classifier signs following cardinals in definite nominal expressions.

Classifiers of this type locate the referents in a specific point in space, so it is not unexpected that they only occur in a definite environment. ${ }^{19}$ Moreover, these classifiers require a discourse antecedent and, as such, they are expected to be included in definite expressions (for discussion, see Barberà \& Quer 2017). Therefore, the presence of these classifiers provides independent evidence for the definite status of the relevant nominal expressions.

Corpus data confirm the pattern that emerged from the elicited data in that: i) indefinite nominal expressions allow for both orders (Card $>\mathrm{N}$ and $\mathrm{N}>\mathrm{Card}$ ), and ii) out of 80 prenominal cardinals, none is connected to pre-established referents. ${ }^{20}$ The general pattern is given in Table 11 . 


\begin{tabular}{|c|c|c|c|c|}
\hline \multirow{2}{*}{ Word order } & \multicolumn{2}{|c|}{ First-mentioned referents } & \multicolumn{2}{c|}{ Pre-established referents } \\
\cline { 2 - 5 } & $\mathbf{n}$ & $\mathbf{\%}$ & $\mathbf{n}$ & $\%$ \\
\hline Card $>\mathrm{N}$ & 80 & 100 & 0 & 0 \\
\hline $\mathrm{N}>$ Card & 70 & 93 & 5 & 7 \\
\hline
\end{tabular}

Table 11: Distribution of cardinals according to referent type (corpus data). X-square (with simulated $\mathrm{p}$-value) $=5.5, \mathrm{p}<.05$.

Interestingly, there are cases in the corpus in which signers introduce new referents by using a numeral expression and then refer back to them later on in the discourse by using another numeral expression. We present and discuss two relevant examples. In the first one, provided in (17), a young signer from Florence talks about her life as deaf mother of a hearing child.

(17) a. HEARING IX-3 ACQUIRE [TWO LANGUAGE]

'(My) hearing child is acquiring two languages.'

b. $\mathrm{GIVE}_{3}$ [LANGUAGE TWO] IMPORTANT

'It is important to give him/her the two languages.'

With respect to the languages mastered by her child, the signer reports that $\mathrm{s} / \mathrm{he}$ is acquiring two languages. The cardinal in (17)a is in prenominal position (TWO LANGUAGE) and conveys a new-discourse information. Later in the discourse, the signer explains that her 
hearing child is acquiring both Italian and LIS. The cardinal in (17)b is in postnominal position (LANGUAGE TWO) and is associated to old-discourse information. As for the NMMs, the cardinal TwO in (17)a is produced with neutral facial expression, whereas the cardinal TwO in (17)b is realized with squinted eyes. The two cardinals look different also with respect to location in space. The former is not directed toward any particular point in space, whereas the latter is produced with a slight forward and downward movement. We consider this movement feature as an additional morpheme that localizes the nominal expression carrying old-discourse information in a specific point in the signing space.

The second example, produced by a middle-aged signer from Florence, is reported in (18).

(18) a. [LATER IX-1 TRY APPLY RELOCATE FLORENCE] [IX-LOC THERE-IS [TWO SISTER] INSIDE]

'Later, I took a shot at applying for relocation in Florence, where I had two sisters.' b. BEFORE [SISTER TWO CL:WHOLE-ENTITY] THINK DIFFERENT TURN 'Before, with my two sisters at home, my mental approach was different, we took turns.'

In (18)a, the signer introduces her two sisters as new referents. Here the cardinal is produced in prenominal position (TWO SISTER). In (18)b, she mentions the same referents again and produces the $\mathrm{N}>$ Card pattern (SISTER TWO). The different NMMs correlate with 
the different discourse interpretations: neutral NMMs occur with new-discourse information, whereas chin down and lowered eyebrows accompany old-discourse information. The definite cardinal construction in (18)b includes a whole-entity classifier sign which locates the two sisters in a specific point in the signing space (as we saw in the elicited data shown in Figure 11).

The fact that word order differences correlate with definite/indefinite interpretation is not a novelty in the literature. Similarly to LIS, in Shupamem (a Bantu language spoken in South Western Cameroon), the position of the cardinal with respect to the noun reveals its semantic interpretation. When the cardinal follows the noun, it yields a definite reading; when it precedes the noun, it is associated with an indefinite reading. The two cases are exemplified in (19) (adapted from Vázquez-Rojas 2011: 235).

$\begin{array}{ll}\text { a. pe? } & \text { pón } \\ \text { two child.PL } \\ \text { 'two children' } \\ \text { b. pón pí pà: } \\ \text { child.PL AGR two } \\ \text { 'the two children' }\end{array}$

When the NP has a definite interpretation, as in (19)b, the cardinal occurs in postnominal position and, interestingly, an agreement marker $(p i)$ appears between noun and cardinal. In 
LIS, too, the cardinal follows the noun when a definite interpretation is involved. As previously discussed, definiteness in LIS is conveyed through NMMs, a DP-internal classifier, or an extra morpheme inducing the cardinal to move toward a point in space. Such a morpheme bears a resemblance to the Shupamem agreement marker $p i$ and might indicate a concord phenomenon. The difference between LIS and Shupamem is that in LIS, the postnominal position is open to cardinals in indefinite expressions as well.

\subsection{Indefinite constructions: specificity and focus}

In order to better understand the word order variation in indefinite constructions, we tested the role of specificity and focus. ${ }^{21}$ On the one hand, cardinals contained in non-specific DPs are expected to behave like MPs in that this construction is by default non-specific (for a discussion on the lack of specificity in MPs, see Bhattacharya 1999). On the other hand, word order is one of the strategies in which focus is marked crosslinguistically (Büring 2009).

As for specificity, Mantovan and Geraci (submitted) show that different degrees of referentiality are normally marked by the use of NMMs, independently of sign order. This is confirmed in the case of NPs modified by cardinals. Indefinite DPs receive a specific interpretation when marked by squinted eyes and a non-specific interpretation when marked by mouth-corners down, as shown in (20).

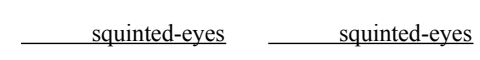


a. THREE BOOK / BOOK THREE (specific interpretation)

mouth-corners down mouth-corners down

b. THREE BOOK / BOOK THREE (non-specific interpretation)

These examples show that specificity: i) is conveyed non-manually, and ii) does not play a role in determining the distribution of LIS cardinals since both pre- and post-nominal cardinals can receive a $[ \pm$ specific $]$ interpretation.

As for focus, we controlled for contrastive, broad, and narrow focus. ${ }^{22}$ The relevant data in (21-23) report acceptability judgments elicited from our informants. Contrastive focus is marked by raised eyebrows, head nod, and forward body lean. In the example in (21), the focalized cardinal is boldfaced. It only occurs in postnominal position.

A. THREE DEAF REGISTRATION-FEE PAY DONE

'Three deaf people paid for the registration fee.'

B. DEAF TWO REGISTRATION WANT / * TWO DEAF REGISTRATION WANT

'TWO deaf people want to register.'

Broad and narrow focus are produced with neutral NMMs. As shown in (22) and (23) respectively, both positions are possible.

(22) A. HAPPEN WHAT 
'What happened?'

\section{B. KID THREE FIGHT / THREE KID FIGHT}

'Three kids had a fight.'

(23) A. MARIA BRING WHAT

'What did Maria bring (to the party)?'

B. MARIA BRING THREE CAKE / MARIA BRING CAKE THREE

'Maria brought three cakes.'

The following table summarizes the word order distribution with respect to the three different kinds of focus we tested.

\begin{tabular}{|c|c|c|c|}
\hline & Contrastive focus & Broad focus & Narrow focus \\
\hline Card $>\mathrm{N}$ & no & yes & yes \\
\hline $\mathrm{N}>$ Card & yes & yes & yes \\
\hline
\end{tabular}

Table 12: Distribution of cardinals according to different kinds of focus.

Qualitative data reveal that contrastive focus plays a role in constraining the distribution of cardinals in indefinite constructions, while specificity does not. 


\section{ANALYSIS}

After considering the available data from both a quantitative and qualitative perspective, a syntactic analysis accounting for the distribution of cardinals in LIS is presented in this section. In particular, we need to explain: i) why indefinite cardinal constructions allow two orders; ii) why cardinals with definite interpretation occur in postnominal position only; iii) why cardinals in MPs are categorically prenominal.

In line with Bertone's (2007) proposal, we assume that nominal constructions in LIS contain the functional DP layer. The head of this projection (D) plays a crucial role in determining the referentiality of the whole construction. In order to derive the different sign order options in LIS, we adopt Cinque's $(2005,2010,2012)$ hierarchy of the DP structure, according to which each nominal modifier comes with two projections: one is assigned to the modifier and the other is a functional agreement projection which is the target of DPinternal movement. The framework also assumes that DP-internal movements must be limited to portions of structure that contain the NP, the maximal projection of the head noun. Within this theoretical framework, we implement Cardinaletti \& Giusti's (2006) proposal that cardinals sit in two distinct projections, namely a DP-external and a DPinternal projection. In article languages, cardinals which are not preceded by a definite determiner are claimed to function as quantifiers and occupy the head of the DP-external Quantifier Projection (QP). When cardinals are preceded by a definite determiner, they are claimed to function as quantitative adjectives (QuantAP) and occupy the specifier position of a lower DP-internal projection. 
Following Cardinaletti \& Giusti (2006), we propose that when cardinals in LIS are included in a construction with an indefinite reading, they are pure quantifiers since they actually quantify over the referent(s) introduced in the discourse. When cardinals appear in a construction with a definite reading, they do not count anything: they are rather nominal modifiers used to refer back to an already mentioned and counted entity. We also follow Bertone (2011) in assuming that some instances of pointing signs correspond to the functional equivalents of definite determiners attested in article spoken languages. ${ }^{23}$ However, as discussed in Section 6.1, definiteness is also signaled by prosodic and/or morphosyntactic cues. The former are specific NMMs (squinted eyes, lowered eyebrows, chin down), the latter consist in a DP-internal classifier or an additional morpheme inducing the cardinal to move slightly forward and downward in a specific point in space (see Section 6.1).

\subsection{Explaining the distribution of cardinals in LIS}

We first start by looking at cases of cardinals in DPs yielding a definite reading. These are cases in which the cardinal must occur in postnominal position. The cardinal functions as a quantitative adjective (QuantAP) and is merged inside the DP structure (Cardinaletti \& Giusti 2006). We assume that in definite constructions, the nominal element (CHILD) obligatorily raises along the structure and moves into the specifier of the DP to gain its referential interpretation. The relevant steps of the derivation are given in (24). The mandatory movement of the noun across the cardinal derives the ungrammaticality of the 
Card $>\mathrm{N}$ order with definite interpretation.

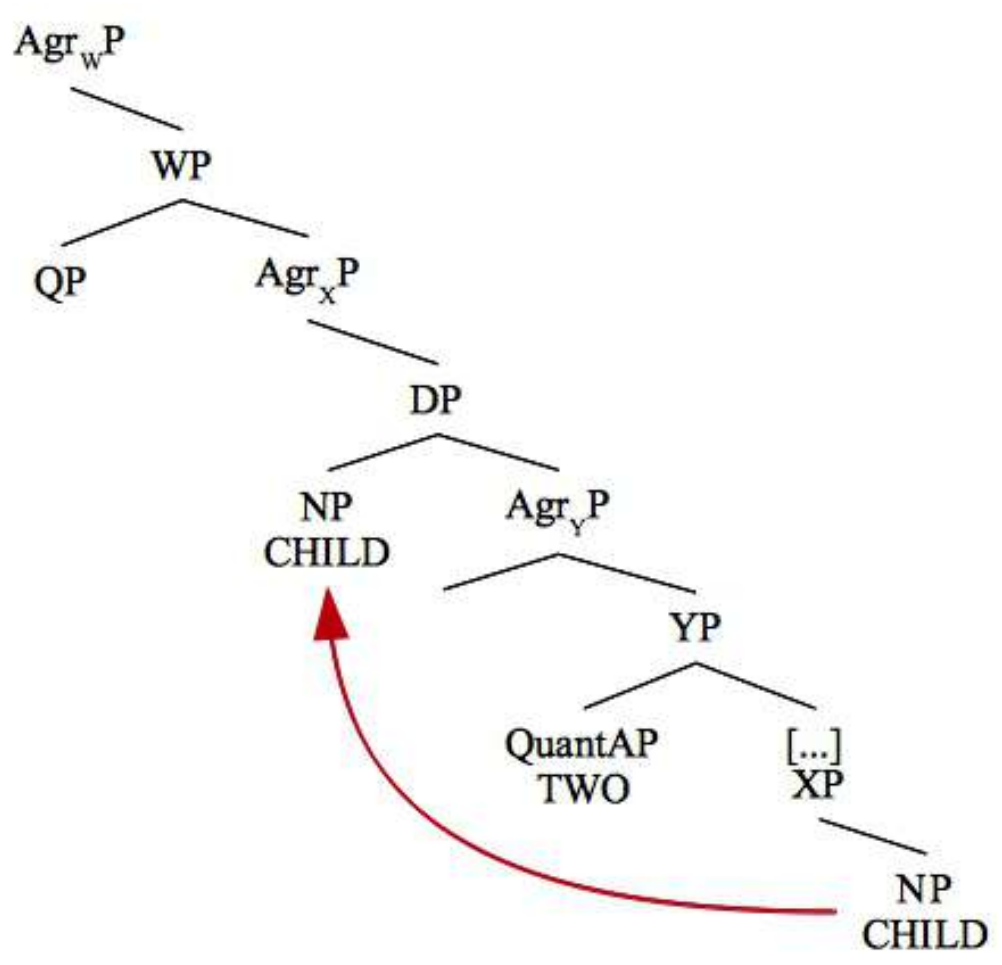

In indefinite constructions, the cardinal functions as a quantifier and occupies a high position in the structure being located in the projection of the quantifier $(\mathrm{QP})$, which sits in the specifier of a functional projection above the DP. ${ }^{24}$ The fact that in these uses the noun may either precede or follow the cardinal can be explained by appealing to optional movement of the noun to a higher projection. The derivation is sketched in (25), where the dashed arrow indicates optionality. 
(25)

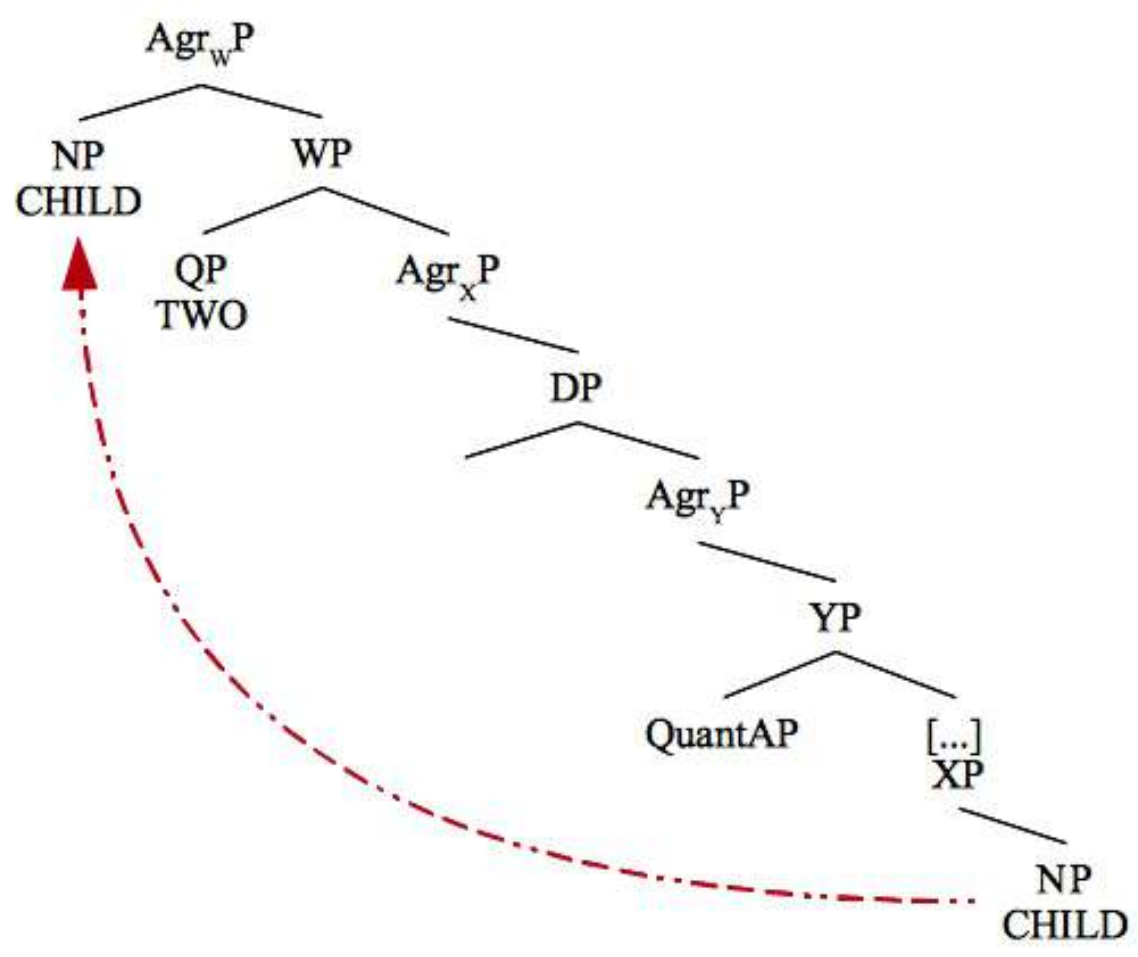

This optionality accounts for the two attested sign orders in indefinite nominal expressions. Being associated with a particular prosodic requirement (e.g., lengthening), contrastive focus may force the cardinal to appear in postnominal position. However, this cannot be the whole story as the $\mathrm{N}>$ Card order in indefinites does not necessarily require contrastive focus. Indeed, focalized phrases aside, our informants do not report any semantic differences in the two orders, which are also associated with the same NMMs (see Section 6.1 and Figure 9 above). In this respect, LIS is different from languages like Russian, where the canonical order is Card $>\mathrm{N}$ and the reversed order ( $\mathrm{N}>\mathrm{Card}$ ) leads to an approximative reading (Yadroff \& Billings 1998: 319). LIS appears to provide an instance of true 
optionality.

\subsection{The syntax of Measure Phrases in LIS}

Explaining the distribution of cardinals contained in MPs implies finding an account for their categorical distribution. An illustrative example of MP is reported in (26). For the sake of clarity, the relevant nominal expression is indicated by square brackets.

\section{(26) [TWO KILO SAUSAGE] IX-1 EAT DONE \\ 'I ate two kilos of sausage.'}

Our proposal is that the measure noun, exemplified by KILO in (26), is not the real head of the NP, but rather it constitutes a complex element together with the cardinal (TWO KILO) that quantifies over a lexical noun (SAUSAGE). It is this nominal element that is the head of the nominal expression. Notice that in LIS MPs, lexical nouns are not preceded by any preposition (cf. Italian due chili di salsicce, transl. 'two kilos of sausages').

Evidence for this analysis is found in (27). The sentence in (27)a has the order Card $>$ Measure $\mathrm{N}>$ Lexical $\mathrm{N}>$ Adjective. Crucially, in (27)b, the lexical noun precedes both the cardinal and the measure noun. This latter order is derived via movement of the lexical noun to the left of the cardinal leaving the measure noun in situ. The derivation is sketched in (28). 
(27) a. [TWO KILO SAUSAGE DELICIOUS] IX-1 BUY DONE

b. ? [SAUSAGE TWO KILO DELICIOUS] IX-1 BUY DONE

'I bought two kilos of delicious sausages.'

(28)

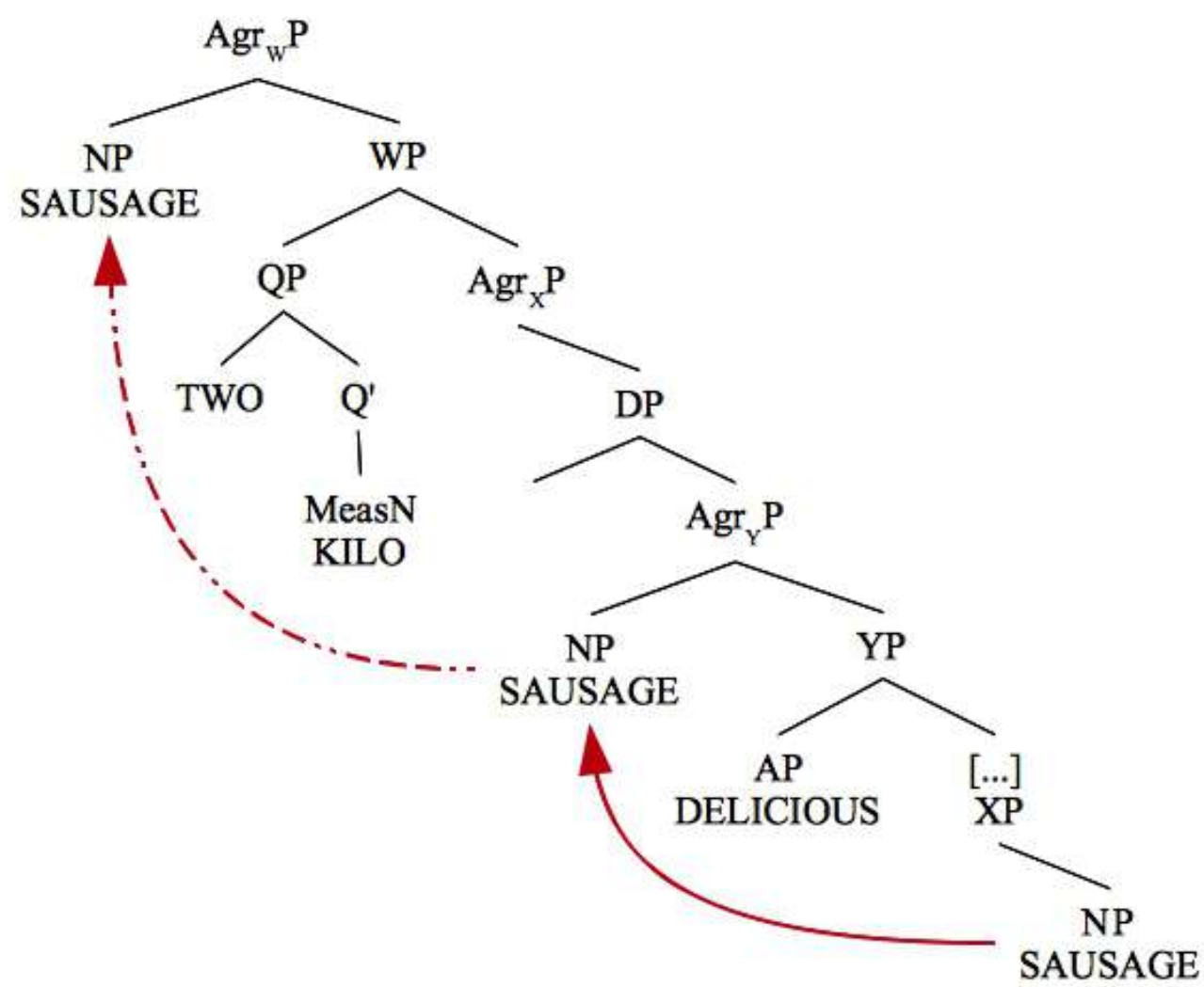

The cardinal sits in the specifier of the QP, while the measure noun (MeasN) sits in its head.

The different order options are derived by moving the head noun (SAUSAGE) obligatorily across the quality adjective (DELICIOUS) and optionally across the MP (TWO KILO).

Since by assumption DP-internal movements are only possible if the moved constituent 
contains the noun (cf. Cinque 2005), we have clear evidence that SAUSAGE in (27)b is the real head noun, as it is the only moving element. As for the quality adjective (DELICIOUS), it is stranded in the lower part of the structure. The fact that in $(27) \mathrm{b}$, both the adjective and the MP are left in situ confirms that the measure noun is not the head noun of the whole construction.

Interestingly, the measure noun must remain adjacent to the cardinal. No lexical material can be inserted between these two elements, as shown in (29)a, ${ }^{25}$ and no order permutation within the MP is allowed, as shown in (29)b.

(29) a. ${ }^{*}$ TWO DELICIOUS KILO SAUSAGE IX-1 BUY DONE
b. ${ }^{*}$ KILO TWO SAUSAGE DELICIOUS IX-1 BUY DONE

The ungrammaticality of (29)b confirms that the noun KILO cannot move as lexical nouns do in the DP.

The lexical noun and the measure noun are not always obligatorily expressed (for relevant discussion on silent elements, see Kayne 2005 and subsequent works). The example in (30) illustrates an instance of silent lexical noun (i.e., the lexical noun DISTANCE is not produced). The examples in (31) illustrate a case of silent measure noun (i.e., the measure noun YEAR is not produced).

(30) IX-1 RUN [TWO KILOMETER Ø] 
'I ran two kilometers.'

(31) a. IX-3 [TWENTY $\varnothing$ AGE]

b. IX-3 [AGE TWENTY $\varnothing]$

'S/he is twenty years old.'

The examples in (30) and (31) differ in a crucial aspect. According to our informants, when the lexical noun is silent, the measure noun can only appear after the cardinal (TWO KILOMETER / * KILOMETER TWO). When the measure noun is silent, the lexical noun can be produced either before or after the cardinal (AGE TWENTY / TWENTY AGE). These facts provide independent evidence for the different status of lexical and measure nouns. On the one hand, only the lexical noun can move along the structure and allows for word order permutations. Thus, it functions as the head of the whole construction. On the other hand, the measure noun must follow the cardinal and cannot move along the structure.

Our speculation is that the strict Card $>$ Measure $\mathrm{N}$ order is derived by the syntactic spechead configuration that characterizes the two elements. In some cases, this spec-head relation results in morphological incorporation/fusion. ${ }^{26} \mathrm{An}$ example of this is the MP THREE-MONTH, shown here in Figure 12. 


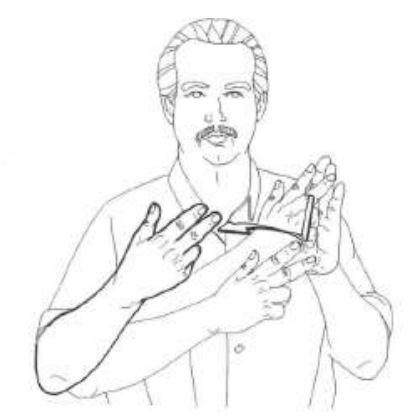

Figure 12: MP incorporation THREE-MONTH.

Other examples of overt incorporation are TWO-DAY, THREE-HOUR, FOUR-YEAR.

\section{CONCLUSIONS}

The cardinal system of human language is quite an intricate topic of study, where different levels of description and explanation intersect. Sign languages offer an even more special viewpoint given the massive use of iconicity especially in the case of digits and numeral incorporation. Crosslinguistic and language-internal variation has been documented in various sign languages (e.g., one-handed vs. two handed systems for digits, how to represent cardinal 10 in two-handed systems, how to represent cardinals above 10, etc.). In their most natural use, cardinal numerals belong to the class of nominal modifiers and interact with the syntax of nominal expressions. Furthermore, at the semantic level, one has a special status in many languages, being ambiguous between a cardinal and a determiner. The picture is even more complicated by the particular sociolinguistic situation of sign languages. As minority languages, sociolinguistic pressure may induce ambiguity as a 
result of transfer from the dominant (spoken) language.

LIS seems to have all these interesting properties: i) it is a 10-base system where complex cardinals are generated by different types of formational strategies (i.e., multiplicative, digital, and additive), ii) it has regional variation at the phonological level, iii) it allows for numeral incorporation, iv) and it displays quite an intricate interaction with the syntax of nominal modification, which is in part regulated by semantic factors like definiteness and focus (distribution of non-manual components, presence vs. absence of whole-entity classifiers, etc.). We capitalized on several of these aspects to provide an account for word order variability within the cartographic approach to syntax. In a general situation of linguistically determined variability, the invariable structure of Measure Phrases in LIS has also been accounted for. Finally, this study provided solid evidence that the sign ONE has undergone a diachronic change. Older signers use ONE both as a cardinal numeral and as an indefinite determiner (like in spoken Italian), while younger signers use ONE almost exclusively as a cardinal. Although more research is needed, this specialization in the function of the sign ONE can be motivated sociolinguistically as a more or less conscious differentiation from spoken Italian.

All in all, this study provides a first overview of the cardinal system in LIS and investigates several phenomena operating at all levels of linguistic description. Some of them show interesting ramifications, which we have to leave to future research. We would like to highlight here two of them: one is numeral incorporation, which seems to be governed by both syntactic and phonological restrictions; the other is the interaction 
between cardinals and overt number marking both at the nominal and verbal level. LIS displays morphological plural by reduplication (although phonologically highly constrained) and verbal number marking (but only in object position), however these agreement/concord systems seem to be optional. A study on the interaction between the cardinal system and other systems of number marking may shed light on these facts. 


\section{REFERENCES}

Barberà, Gemma. 2012. The meaning of space in Catalan Sign Language (LSC). Reference, specificity and structure in signed discourse. Ph.D. Dissertation, Universitat Pompeu Fabra.

Barberà, Gemma \& Josep Quer. 2017. Nominal referential values of semantic classifiers and role shift in signed narratives. In Annika Hübl \& Markus Steinbach (eds.), Linguistic foundations of narration in spoken and sign languages. Amsterdam: Benjamins.

Barrett, Rusty. 2008. Linguistic differentiation and Mayan language revitalization in Guatemala. Journal of Sociolinguistics 12(3), 275-305.

Bertone, Carmela. 2007. La struttura del sintagma determinante nella Lingua dei Segni Italiana (LIS). Ph.D. dissertation, Ca' Foscari University.

Bertone, Carmela. 2009. The syntax of noun modification in Italian Sign Language (LIS). University of Venice Working Papers in Linguistics 19, 7-28.

Bertone, Carmela. 2011. Fondamenti di grammatica della lingua dei segni italiana. Milano: Franco Angeli.

Bhattacharya, Tanmoy. 1999. Specificity in the Bangla DP. In Rajendra Singh (ed.), Yearbook of South Asian Languages and Linguistics 2, 71-99. New Delhi/London: Sage Publications.

Borer, Hagit. 2005. In Name Only. Structuring Sense 1, ch. 7. Oxford: Oxford University 
Press.

Branchini, Chiara. 2007. On relativization and clefting in Italian Sign Language (LIS).

Ph.D. dissertation, University of Urbino.

Branchini Chiara \& Carlo Geraci. 2011. L'ordine dei costituenti in LIS: risultati preliminari. In Anna Cardinaletti, Carlo Cecchetto \& Caterina Donati (eds.), Grammatica, lessico e dimensioni di variazione nella LIS, 113-126. Milano: Franco Angeli.

Branchini Chiara, Anna Cardinaletti, Carlo Cecchetto, Caterina Donati \& Carlo Geraci. 2013. Wh- duplication in Italian Sign Language. Sign Language \& Linguistics, 16(2), $157-188$.

Brunelli, Michele. 2011. Antisymmetry and sign languages. A comparison between NGT and LIS. Utrecht: LOT Publications.

Büring, Daniel. 2009. Towards a Typology of Focus Realization. In Malte Zimmermann \& Caroline Féry (eds.), Information Structure: theoretical, typological and experimental perspectives, 177-205. Oxford: Oxford University Press.

Cardinaletti, Anna, Carlo Cecchetto \& Caterina Donati (eds.). 2011. Grammatica, lessico e dimensioni di variazione nella LIS. Milano: Franco Angeli.

Cardinaletti, Anna \& Giuliana Giusti. 2006. The syntax of quantified phrases and quantitative clitics. In Martin Everaert \& Henk van Riemsdijk (eds.), The Blackwell companion to syntax, vol. V, 23-93. Oxford: Blackwell Publishing.

Cecchetto, Carlo, Carlo Geraci \& Sandro Zucchi. 2006. Strategies of relativization in Italian Sign Language. Natural Language \& Linguistic Theory, 24(4), 945-975. 
Cecchetto, Carlo, Carlo Geraci \& Sandro Zucchi. 2009. Another way to mark syntactic dependencies: The case for right-peripheral specifiers in sign languages. Language $85(2), 278-320$.

Cinque, Guglielmo. 2005. Deriving Greenberg's Universal 20 and its exceptions. Linguistics Inquiry 36, 315-332.

Cinque, Guglielmo. 2010. The syntax of adjectives. Cambridge, MA: MIT Press.

Cinque, Guglielmo. 2012. A partial map of extended functional projection of the NP. Class lecture in advanced syntax, a.y. 2011/2012, Ca' Foscari University of Venice.

Cohen, Jacob. 1989. Statistical power analysis for the behavioral sciences. New York: Lawrence Erlbaum Associates.

Corazza, Serena. 1990. The morphology of classifier handshapes in Italian Sign Language (LIS). In Ceil Lucas (ed.), Sign Language Research. Theoretical Issues, 71-82. Washington, DC: Gallaudet University.

Corbett, Greville G. 1978. Universals in the syntax of cardinal numbers. Lingua 46, 355368.

Corver, Norbert. 2009. Getting the (syntactic) measure of Measure Phrases. The Linguistic Review 26(1), 67-134.

Dryer, Matthew S. 2013. Indefinite Articles. In Matthew S. Dryer \& Martin Haspelmath (eds.), The World Atlas of Language Structures Online. Leipzig: Max Planck Institute for Evolutionary Anthropology (available online at http://wals.info/chapter/38, Acc. On 2017-06-14). 
Fischer, Susan D. 1996. By the numbers: language-internal evidence for creolization. In William H. Edmondson \& Ronnie B. Wilbur (eds.), International review of sign linguistics. Vol. 1, 1-22. Hillsdale, NJ: Erlbaum.

Franks, Steven. 1994. Parametric properties of numeral phrases in Slavic. Natural Language \& Linguistic Theory 12, 597-674.

Geraci, Carlo, Robert Bayley, Chiara Branchini, Anna Cardinaletti, Carlo Cecchetto, Caterina Donati, Serena Giudice, Emiliano Mereghetti, Fabio Poletti, Mirko Santoro \& Sandro Zucchi. 2010. Building a corpus for Italian Sign Language: Methodological issues and some preliminary results. Language Resources and Evaluation Conference (LREC), 98-101.

Geraci, Carlo, Katia Battaglia, Anna Cardinaletti, Carlo Cecchetto, Caterina Donati, Serena Giudice \& Emiliano Mereghetti. 2011. The LIS Corpus Project. A discussion of sociolinguistic variation in the Lexicon. Sign Language Studies, 11(4), 528-574.

Geraci, Carlo. 2012. Language Policy and Planning: The Case of Italian Sign Language. Sign Language Studies, 12(4), 494-518.

Greenberg, Joseph H. 1963. Some universals of grammar with particular reference to the order of meaningful elements. In Joseph H. Greenberg (ed.), Universals of Human Language, 73-113. Cambridge, MA: MIT Press.

Hanke, Thomas. 2010. Additional rarities in the typology of numerals. In Jan Wohlgemuth \& Michael Cysouw (eds.), Rethinking universals: How rarities affect linguistic theory, 61-89. Berlin: De Gruyter Mouton. 
Hurford, Jim. 2003. The interaction between numerals and nouns. In Frans Plank (ed.), Noun Phrase structure in the languages of Europe. Typology of languages in Europe, 561-620. The Hague: De Gruyter Mouton.

Ionin, Tania \& Ora Matushansky. 2006. The composition of complex cardinals. Journal of Semantics 23, 315-360.

Jackendoff, Ray S. 1972. Semantic Interpretation in Generative Grammar. Cambridge, MA: MIT Press.

Johnston, Trevor \& Onno Crasborn. 2006. The use of ELAN annotation software in the creation of sign language corpora. Presentation at Electronic Metastructure for Endangered Languages Data (E-MELD). Lansing, MI. June 20-22.

Kayne, Richard. 2005. Movement and Silence. New York: Oxford University Press.

Kayne, Richard. 2016. Some Thoughts on One and Two and Other Numerals. Unpublished manuscript, New York University.

Koulidobrova, Elena \& Diane Lillo-Martin. 2016. Point of inquiry: The case of the (non-) pronominal IX in ASL. In Patrick Grosz \& Pritty Patel (eds.), Impact of Pronominal Form on Interpretation, 221-250. Berlin: De Gruyter Mouton.

Ladd, D. Robert. 1996. Intonational phonology. Cambridge: Cambridge University Press.

Mantovan, Lara \& Carlo Geraci, 2017. The syntax of nominal modification in Italian Sign Language (LIS), Sign Language \& Linguistics 20(2), 183-220.

Mantovan, Lara \& Carlo Geraci, submitted. R-impersonal interpretation in LIS.

Mantovan Lara, Kyle Duarte, Carlo Geraci \& Anna Cardinaletti. 2016. Access to 
knowledge: the issue of deaf students and more. Annali di $\mathrm{Ca}^{\prime}$ Foscari, serie Occidentale 50, 149-164.

Mazzoni, Laura. 2008. Classificatori e impersonamento nella lingua dei segni italiana. Pisa: PLUS-Pisa University Press.

Ohser, Erich. 2000. Politische Karikaturen, Zeichnungen, Illustrationen und alle Bildgeschichten Vater und Sohn. Konstanz: Sudverlag GmbH.

Radutzky, Elena. 2001. Dizionario bilingue elementare della lingua italiana dei segni. Roma: Edizioni Kappa.

Rooth, Mats. 1985. Association with Focus. Ph.D. Dissertation, University of Massachusetts, Amherst.

Tang, Gladys \& Felix Sze. 2002. Nominal expressions in Hong Kong Sign Language: Does modality make a difference? In Richard P. Meier, Kearsy A. Cormier \& David G. Quinto-Pozos (eds.), Modality and structure in signed and spoken languages, 296-321. Cambridge, UK: Cambridge University Press.

Vázquez-Rojas, Violeta. 2011. Definite and indefinite numeral phrases in Shupamem. In Neil Myler \& Jim Wood (eds.), New York University Working Papers in Linguistics (NYUWPL), vol. 3, 231-244.

Yadroff, Michael \& Loren Billings. 1998. The syntax of approximative inversion in Russian (and the general architecture of nominal expressions). In Željko Bošković, Steven Franks \& William Snyder (eds.), Formal approaches to Slavic linguistics: The Connecticut Meeting 1997, 319-338. AnnArbor, MI: Michigan Slavic Publications. 
Zeshan, Ulrike, Cesar Ernesto Escobedo Delgado, Hasan Dikyuva, Sibaji Panda \& Connie de Vos. 2013. Cardinal numerals in rural sign languages: Approaching cross-modal typology. Linguistic Typology 17, 357-396.

Zweig, Eytan. 2006. Nouns and adjectives in numeral NPs. In Leah Bateman \& Cherlon Ussery (eds.), Proceedings of NELS 35, vol. 2, 663-679. Amherst, Massachusetts: University of Massachusetts, GLSA. 
Author's address: (to be added)

1 Although English one is often interpreted as cardinal, there are cases in which it functions as determiner, e.g., 'One day, he'll realize that we were right' (Kayne 2016).

2 Bertone (2007) claims that this sentence can be realized with the following alternative order: [BOOK TWO NEW IX_DEM] POSS-1. Ungrammatical options are: * TWO IX-DEM BOOK NEW, * IX-DEM TWO BOOK NEW, * BOOK IX-DEM NEW TWO, * NEW BOOK TWO IXDEM. According to the author, the pointing sign functioning as demonstrative (here labeled as IX-DEM) typically occurs at the end of the DP and encodes space features.

3 Branchini (2007) reports the following very dubious case as well: ?? CHILDREN IXDEM/IX THREE ICE-CREAM LIKE.

4 The repetition cases, $\operatorname{Card}>\mathrm{N}>\mathrm{Card}$ and $\mathrm{N}>\mathrm{Card}>\mathrm{N}$, are omitted as irrelevant.

5 Unless differently indicated, standard Pearson's X-square test has been conducted. In some cases, p-values were computed by using Monte Carlo simulation to avoid incorrect approximations. Power analysis has been conducted for each X-square test reported in the paper. Unless differently specified, we used the following parameters: effect size, $w=0.3$ and significance level, $\mathrm{p}=.05$ (Cohen 1989). Significant $X$-square values are reported only for power values $>.80$.

6 The explanatory drawings included in Section 2 as well as Figure 12 are taken from Radutzky (2001). They refer to the most widespread variants in Italy. The LIS cardinals from 1 to 10 make iconic reference to manual counting and are straightforwardly 
interpretable, however it is worth noting that this is not always the case in the world's sign languages. For instance, American Sign Language (ASL) signers use one hand in ten different handshapes to express cardinals from 1 to 10 (Fischer 1996).

7 Further details on the possible phonological realizations of the sign ONE are discussed in Section 5.1 .

8 With respect to cardinals from 6 to 10, sign languages show interesting variation (see Fischer 1996). French Sign Language (LSF) is similar to LIS from 6 to 9, but 10 is not produced by extending ten digits. It is a two-handed sign involving the F handshape, with the loop of the F representing 0. ASL signers use one hand and differentiate cardinals from 1 to 5 and from 6 to 10 by selecting different fingers. Cardinals from 6 to 10 in Argentine Sign Language (LSA) are one-handed signs and touch different parts of the body.

9 However, Ionin \& Matushansky (2006) claim that the composition of complex cardinals cannot be accounted for by extra-linguistic constraints (i.e., arithmetic operations) only. Well-attested phenomena such as number marking and Case assignment suggest that principles of semantic composition should be considered as well. Since the morphological interaction between cardinal and noun is not investigated in this study, we leave the question whether cardinal formation in LIS is consistent with this proposal for future research.

10 Finger bending in tens is probably motivated by the fact that moving the index finger 
toward the thumb is reminiscent of the shape of 0 .

11 Another way to express cardinals from 16 to 19 involves the additive strategy. These variants, attested in Northern Italy, are produced first by signing TEN with outward palm orientation, then by moving both hands in opposite directions in the vertical plane and showing how many units are involved.

12 Once removed the ambiguous cases, the comparison between older and younger signers is only marginally significant $(\mathrm{X}$-squared test with simulated $\mathrm{p}$-value $=4.05, \mathrm{p}<.1$ ). However, given the small number of tokens (39), the results are only reliable for a large effect size. Values for the Power analysis: $\mathrm{w}=0.5$, sig. Level $=.05$, Power $=.87$.

13 Values for the Power analysis: $\mathrm{w}=0.5, \mathrm{df}=1$, sig. level $=.05, \mathrm{~N}=43$, Power $=.90$.

14 Unfortunately, the number of tokens is not enough to run a X-square test even for large effect size. For $\mathrm{w}=0.5, \mathrm{df}=1$, sig. level $=.5$, Power $=80$ the number of tokens required is 32 .

15 The patterns concerning the palm orientation of determiner ONE and cardinal ONE have been identified according to corpus data. Data elicitation is needed in order to confirm these data.

16 The difference is significant $(\mathrm{X}$-square $=43.04, \mathrm{p}<.001$, Power $=.77)$.

17 Generally speaking, the term classifier is used to denote a particular handshape that refers to a class of referents sharing a common property (e.g., shape, size, the manner in which the object is handled, etc.). For studies on classifiers in LIS, the reader is referred 
to Corazza (1990) and Mazzoni (2008).

18 The whole-entity classifiers presented and discussed in this section should not be confused with the classifiers used in numeral classifier languages like Mandarin (for an overview, see Hurford 2003: Section 3). In these languages, the occurrence of the classifier is obligatory in numeral expressions, whereas in LIS (in the uses described in this paper) whole-entity classifiers are optionally expressed in definite DPs containing a cardinal.

19 According to Bertone (2007: 169), in LIS the location of the classifier plays an important role in determining the nature of the related head noun in terms of definiteness. In other words, the classifier encodes the referentiality of the noun it is associated with.

20 The data of the previous studies on LIS reported in Section 2 (Bertone 2007, Branchini 2007, Brunelli 2011) are coherent with our conclusions. In particular, examples (5) and (6) display a definite expression containing a demonstrative and both feature a postnominal cardinal. The example in (7) is indefinite and contains a postnominal cardinal, one of the two available options in this case.

21 We are grateful to Tania Ionin for suggesting this line of enquiry.

22 Broad and narrow focus are typically used to convey new information in a discourse (for more details, see Ladd 1996). For illustrative purposes, in the following examples, the focus domain is underlined. Broad focus would be used to answer to the general 
question 'What happened?' (e.g., 'Mary bought two laptops'), whereas narrow focus would be used to answer to a question with a wh- element asking for a certain constituent, such as 'What did Mary buy?' (e.g., 'Mary bought two laptops'). The third type of focus discussed in this paper, i.e., contrastive focus (Jackendoff 1972 and Rooth 1985), is used to correct a piece of information, as in the following discourse stretch: 'You invited Mary?', '(No,) I invited Tom'.

23 With respect to the pointing signs co-occurring with nouns in LIS, Bertone (2007: 158) claims that these elements function as demonstratives rather than articles. In line with Bertone's view, Brunelli (2011: 56) claims that LIS does not display definite articles. A different perspective is offered in Bertone (2011: 126), where DP-internal pointing signs are considered demonstratives when they are compulsory and articles when they are optional and very brief (and the pointing is to a non-specified location). More systematic studies are needed in order to explain the function of determiner-like pointing signs (for ASL, Koulidobrova \& Lillo-Martin 2016 argue that these signs are better analyzed as demonstratives rather than definite articles).

24 In Cinque's framework $(2005,2012)$, quantifiers are not found in the backbone of the extended projection of the NP, but they sit in the specifier of a dedicated functional projection. Differently from Cinque (2005), Cardinaletti \& Giusti (2006) analyze QP as a projection that directly dominates the extended projection of the NP and selects the DP as its complement. What is relevant here is that the quantifier occupies a DP- 
external position.

25 Although adjectives in LIS usually follow the noun, some evaluative adjectives like BEAUTIFUL may sometimes precede the noun (Mantovan \& Geraci 2017).

26 Whether numeral incorporation is a syntactic or a phonomorphologic phenomenon (or maybe both) is an intriguing issue which we leave for future research. 